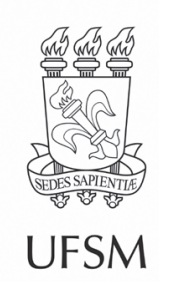

\title{
Artigos
}

\section{Mapeamento dos problemas associados à geração e tratamento das cinzas na combustão da biomassa florestal em caldeira}

\author{
Problem mapping of the generation and treatment of forest biomass \\ ashes in boiler
}

\author{
Martha Andreia Brand ${ }^{\oplus}$ \\ Reny Aldo Henne" $\odot$ \\ Viviane Aparecida Spinelli Schein ${ }^{\oplus}$ \\ Ederson Rodrigues Pereira"II $\odot$
}

\author{
'Universidade do Estado de Santa Catarina, Lages, SC, Brasil \\ "Centro Universitário Unifacvest, Lages, SC, Brasil \\ I"Pilar Produtos Agroecológicos, Bom Retiro, SC, Brasil
}

\section{RESUMO}

Os problemas relacionados à combustão da biomassa e o seu impacto sobre a eficiência das caldeiras dependem das características do combustível e do projeto e operação dos equipamentos. Assim, este estudo teve como objetivo mapear os problemas associados à geração, coleta e tratamento das cinzas da biomassa florestal queimada em caldeiras industriais. O estudo foi realizado em uma usina termelétrica que gera $28 \mathrm{MW} / \mathrm{h}$ ora e usa biomassa florestal como combustível. Foram feitas três coletas de cavacos de madeira, antes da entrada na fornalha da caldeira e em quatro locais de passagem de cinzas na caldeira, onde ocorre o tratamento e recolhimento para disposição final deste resíduo da biomassa. Parte do mix de biomassa foi calcinado em laboratório para comparação entre os pontos de amostragem com as propriedades da biomassa. As propriedades analisadas foram: composição química elementar inorgânica; teste de fusão das cinzas e a potencialidade de ocorrência de problemas por meio dos índices de: deposição das cinzas (R); escória (Rs); incrustação (Fu); viscosidade (Sr) e álcali (Al). Os compostos presentes em maior concentração nas cinzas foram os óxidos de silício, alumínio, ferro, cálcio, potássio e magnésio. A temperatura de fusão das cinzas foi entre $1261^{\circ} \mathrm{C}$ e $1385^{\circ} \mathrm{C}$. O mapeamento dos problemas apontou baixos riscos de formação de escória e viscosidade. O índice de incrustação foi alto para o decantador $(0,69)$ e o readler teve médio potencial de viscosidade $(1,11)$. A formação de álcali ocorreu no readler e decantador, provocando corrosões nestes pontos. Os cálculos dos índices de deposição foram capazes de expressar os problemas que ocorrem na queima da biomassa florestal em caldeira.

Palavras-chave: Análise elementar; Fusão das cinzas; Índices de deposição 


\section{ABSTRACT}

The nature of the problems associated with the biomass combustion in boilers and their impact on the performance of combustion equipment depends on the fuel's characteristics, and the design and operation of the combustion equipment. Thus, the objective of this study was to map the problems associated with the generation and treatment of forest biomass ashes in an industrial boiler. The study was developed in a thermoelectric plant with a production of $28 \mathrm{MW} /$ hour originated from the combustion of residual forest biomass. Three biomass samples were collected before entering the boiler's furnace and at four flowing points inside the boiler, where the treatment and recovery for the final disposal of the biomass ashes occur. To compare the collection points in the boiler and the biomass properties, part of the samples were calcined in the laboratory. The analysed properties were: inorganic elemental chemical composition; the ashes fusion test and the potentiality of occurrence of problems through the following indices: ash deposition (R); slag (Rs); inlay (Fu); viscosity (Sr) and alkali (Al). As for the elemental chemical composition, the compounds with the highest concentrations were silicon, aluminum, iron, calcium, potassium and magnesium oxides. The melting temperature of the ashes was between $1261{ }^{\circ} \mathrm{C}$ and $1385^{\circ} \mathrm{C}$ at the collection points. The mapping of the problems indicated low risks of formation of slag and viscosity. The fouling index was high, from 0.69 for the decanter and 1.11 for the readler, the latter having a medium potential viscosity. The formation of alkali occurred in the readler and decanter, causing corrosion at these points. The calculations of the deposition rates, based on the elemental chemical composition of the ashes were able to express the problems that occur in the combustion of the forest biomass in the boiler.

Keywords: Elemental analysis; Fusion of the ashes; Indices of the deposition

\section{INTRODUÇÃo}

Quando uma partícula de combustível queima, em função das elevadas temperaturas, o equilíbrio da fração inorgânica da cinza ocorre devido a passagem desta por várias transformações físicas e químicas simultâneas (ABRAHAM et al., 2013; NUNES et al., 2016). Assim, as partículas de cinza são resultado de processos de evaporação, precipitação, separação, coalescência e nucleação, tendo um amplo range de composição, forma e tamanho. No entanto, esses fenômenos dependem de vários fatores, como composição do combustível e morfologia, tempo de residência do combustível e temperatura de combustão durante a queima (NUNES et al., 2016).

Alguns problemas estão associados à combustão de qualquer combustível. Em função disso, Capehart, Turner e Kennedy (2005) destacaram a importância de se questionar: quais problemas podem ser gerados pelos resíduos e cinzas durante a combustão do combustível em caldeira? 
De forma geral, os problemas gerados pelas cinzas na combustão da biomassa em caldeiras estão relacionados com: (1) a formação de aglomerados de cinzas parcialmente fundida, e sua influência sobre as deposição (depósitos) na grelha e de escória em altas temperaturas, devido a problemas de manuseio, defluidização, condições de combustão inadequadas e remoção de cinzas; (2) em zonas de baixa temperatura, formação de depósitos de cinzas nas superfícies de troca de calor em caldeiras com secções convectivas; (3) corrosão acelerada; (4) erosão do metal onde ocorre a passagem dos gases, em função da emissão de cinzas em aerossol; (5) acúmulos e posterior desprendimento e queda de depósitos da parte superior da caldeira, representando riscos aos componentes do sistema de combustão (SOMMERSACHER et al., 2011; LAMBERG et al., 2013; NUNES et al., 2016).

Os tipos de problemas e o seu efeito sobre a eficiência das caldeiras depende das propriedades do combustível (principalmente a composição química inorgânica e o teor de cinzas), bem como do projeto construtivo e operação do equipamento (CHERNEY; VERMA, 2013). Os compostos inorgânicos, que constituem a composição química das cinzas, se apresentam na biomassa como óxidos alcalinos e sais e estão relacionados aos problemas de deposição, aglomeração e corrosão nas superfícies de transferência de calor da caldeira (WERTHER et al., 2000). Além da composição da cinza, também os parâmetros térmicos, físicos e químicos locais influenciam a deposição de partículas de cinzas nas superfícies de troca de calor e paredes refratárias das caldeiras e a formação de fases fundidas (MASIÁ et al., 2007).

Juntamente com a composição química inorgânica, o comportamento em temperaturas elevadas e o ponto de fusão das cinzas são as características mais importantes da biomassa enquanto combustível (WIINIKKA; GRÖNBERG; BOMAN, 2013). O desempenho sólido-líquido da cinza (fusão) é um fenômeno muito complexo. Estudos mostram que a fusão ocorre durante um intervalo de várias centenas de graus, a partir do ponto eutético (TEIXEIRA et al., 2012). Portanto, além do projeto da caldeira e das condições de operação determinarem fortemente a deposição das cinzas, o entendimento do comportamento de fusão das cinzas é crucial (MASIÁ et al., 2007). 
Para expressar os problemas ligados à queima da biomassa, são determinados os índices de deposição, por meio de diferentes equações e correlações, já bem estabelecidas na literatura (PRONOBIS, 2005). Entre os índices mais conhecidos estão: o índice de escória, viscosidade, álcali e incrustação (GUPTA et al., 1998). Esses índices são calculados considerando a composição química inorgânica da biomassa. Existe uma clara ligação entre os resultados obtidos pelas correlações e índices descritos anteriormente e a composição química dos combustíveis (MASIÁ et al., 2007).

Nesse contexto, a problemática de pesquisa que se coloca neste tema é: qual a influência da constituição química inorgânica da biomassa florestal na ocorrência de problemas gerados na sua combustão em caldeiras, para a geração de energia térmica? A partir disso, a hipótese de pesquisa é que a composição química elementar da biomassa florestal indicará contaminação por terra, areia e outros agentes externos. Além disso, essa contaminação contribuirá para diferenças nos problemas de deposição observados nos vários pontos de produção e coleta das cinzas dentro da caldeira. Porém, de forma geral, a biomassa terá baixo potencial de geração de problemas de combustão em caldeira.

Portanto, em estudos que visam a determinação dos problemas associados à formação das cinzas em caldeira pela combustão da biomassa florestal, são fundamentais as análises (1) da composição química elementar inorgânica da biomassa e das suas cinzas, e (2) do ponto de fusão das cinzas geradas nos sistemas de combustão das caldeiras. Assim, para responder ao problema de pesquisa posto e comprovar a hipótese levantada, o objetivo deste trabalho foi determinar os problemas associados à geração e tratamento das cinzas na combustão da biomassa florestal em caldeira industrial de uma termelétrica. 


\section{MATERIAL E MÉTODOS}

A biomassa e as cinzas utilizadas neste estudo foram coletadas em uma termelétrica (produção de 28MW/hora), localizada em Lages - SC (2748'34.5"S $50^{\circ} 22^{\prime} 34.9^{\prime \prime}$ W). O combustível utilizado na usina é composto de $70 \%$ de cavaco, $25 \%$ de serragem e $5 \%$ casca, destopos e toretes, originários de plantios florestais e indústrias de transformação mecânica da madeira. As espécies que compõe a biomassa são pinus $(99,5 \%)$ e eucalipto (0,5\%). O consumo médio de cavacos é de $58 \mathrm{t} / \mathrm{h}$, com $50 \%$ de umidade (base úmida). As temperaturas na câmara de combustão são em torno de 800 a $1000^{\circ} \mathrm{C}$.

A parte da usina destinada à geração do vapor é composta por fornalha, caldeira, superaquecedor, economizador e aquecedor de ar. A biomassa queima na fornalha, que tem 6 locais de alimentação do biocombustível na sua parte frontal. Neste local (Figura 1 (6)) foi coletada a biomassa, antes da entrada na câmara de combustão. A mistura queimada era constituída de cavacos, serragem e casca, com umidade de 60,14\% (base úmida). Na câmara de combustão, o sistema de queima é composto por grelha fixa, onde o combustível queima em uma camada com 30-40 cm.

Durante o processo de combustão, as cinzas pesadas são recolhidas no fundo da fornalha por meio de um selo d'água e recolhida pelo Readler (1) (Figura 1 (1)). Neste ponto foi coletada a amostra de cinzas com maior nível de contaminação, como fragmentos de pedras, areia e cavacos parcialmente carbonizados, com umidade entre 37-38\% (base úmida). As cinzas leves são levadas juntamente com os gases, em direção aos superaquecedores, na parte superior da fornalha. Após este ponto, as cinzas passam pela Tremonha (Figura 1(2)), que é um duto onde também há a extração de cinzas. Neste ponto foi coletada uma amostra de cinzas leves, por se tratar de material com menor granulometria ( $<1,0 \%$ de umidade). Após este ponto, as cinzas são levadas para o Pré-Ar e Lavador de gases (Figura 1(3)), passando pelo selo de água e depois coletadas e conduzidas à peneira rotativa que separa as cinzas grossas 
das finas. Na peneira rotativa foi realizada a coleta de mais uma amostra de cinzas, também com pequena granulometria e teor de umidade de (86-87\%). As cinzas finas são encaminhadas para o Decantador (Figura 1 (4)). O decantador bombeia o fluído com as cinzas para um filtro lavador. Na saída do filtro lavador foi obtida a última amostra de cinzas, com granulometria ainda menor que no ponto de amostragem anterior e com menor teor de umidade (57\%).

Figura 1 - Esquema da passagem das cinzas da combustão da biomassa e dos pontos de coleta das amostras analisadas na caldeira

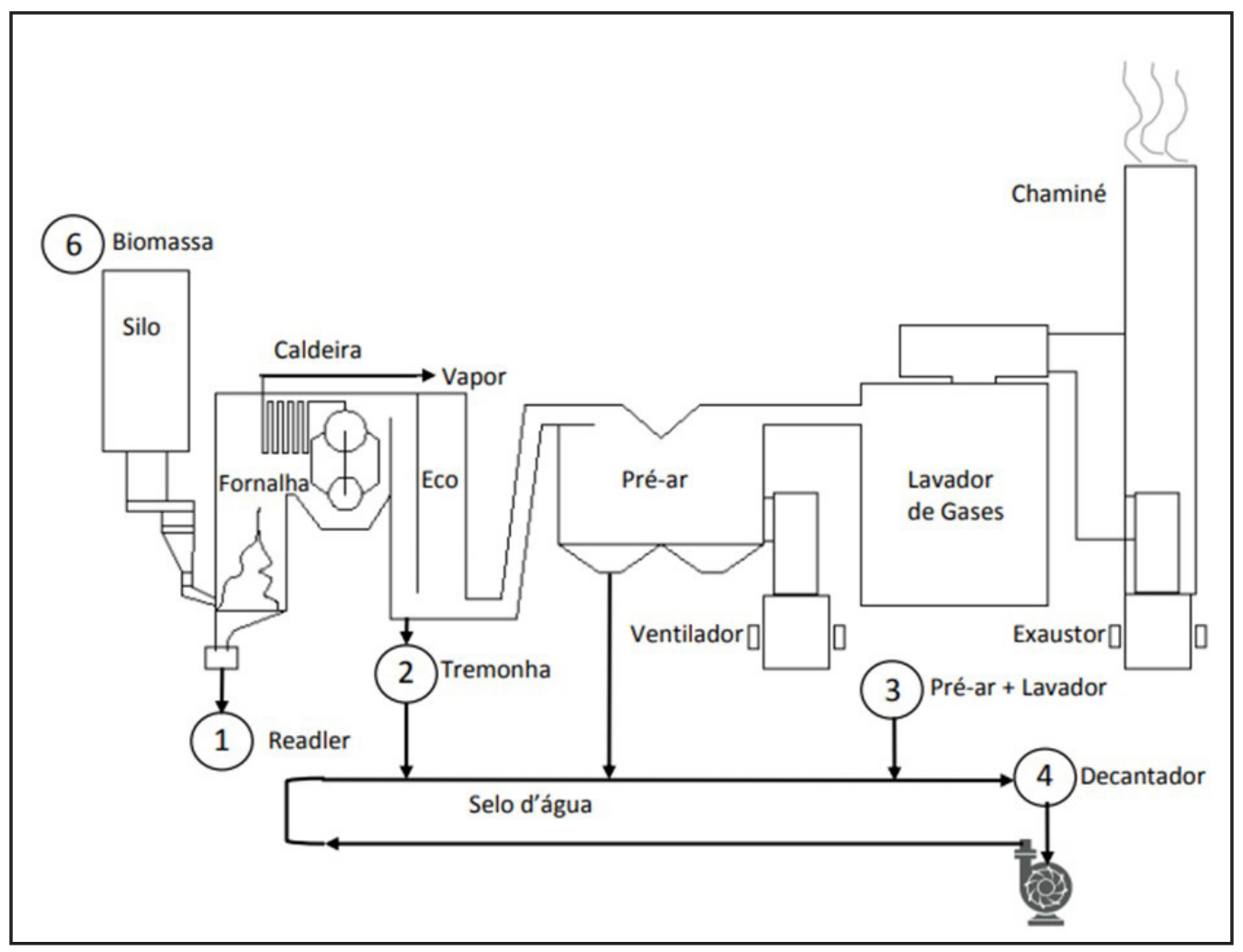

Fonte: Henne et al. (2019)

A amostra denominada de cinza da biomassa foi produzida por calcinação, em mufla, à temperatura de $1.000^{\circ} \mathrm{C}$ por um período de 3 horas, a partir da biomassa coletada antes da entrada na fornalha. Este procedimento foi feito para possibilitar a combustão perfeita da biomassa e obtenção de um material livre ou praticamente livre de carbono. Esta amostra permitiu a comparação com as cinzas produzidas na queima da biomassa em caldeira. Assim, é possível visualizar a eficiência da caldeira. 
Foram coletados $5 \mathrm{~kg}$ de cada material analisado. Foram realizadas três coletas (Tabela 1), onde os parâmetros de operação foram registrados para análise das variações ocorridas no funcionamento da usina.

Tabela 1 - Parâmetros de operação da caldeira que apresentaram variações durante as coletas das amostras

\begin{tabular}{lccc}
\hline \multirow{2}{*}{ Parâmetros de operação } & \multicolumn{3}{c}{ Datas de coleta (2017) } \\
\cline { 2 - 4 } & $\mathbf{3 1 / 0 5}$ & $\mathbf{0 8 / 0 8}$ & $\mathbf{1 4 / 1 1}$ \\
\hline Vazão de entrada água ton/h & 66,40 & 91,20 & 89,10 \\
Vazão vapor (ton/h) & 64,10 & 91,30 & 89,30 \\
Grupo Gerador & & & \\
Potência ativa kW & 12528,00 & 20976,00 & 20878,00 \\
Potencia Regenerativa kW & $-1008,00$ & 5376,00 & 5039,00 \\
Ar e Gases & & & \\
Ar Secundário ent., mmca & 211,80 & 484,40 & 380,43 \\
Ar Secundário Saída Pré-Ar, mmca & 202,80 & 469,90 & 420,32 \\
Ar primário ent. Pré-ar, mmca & 30,24 & 35,59 & 33,83 \\
Ventilador Ar primário, mmca & 30,24 & 35,59 & 34,33 \\
Ventilador Ar primário \% & 34,03 & 46,00 & 35,33 \\
Ventilador Ar secundário mmca & 211,80 & 484,40 & 394,05 \\
Ventilador Ar secundário \% & 0,18 & 0,40 & 0,38 \\
Gases Entrada Pré-Ar, mmca & $-7,01$ & $-17,73$ & $-15,39$ \\
Pressão saída Eco mmca & $-24,52$ & $-51,87$ & $-39,51$ \\
Exaustor 1\% & 27,70 & 44,90 & 40,85 \\
Exaustor 2\% & 27,70 & 44,90 & 40,85 \\
\hline
\end{tabular}

Fonte: Autores (2021)

A limpeza das grelhas, que leva as cinzas para o readler, é realizada a cada oito horas. Seis conjuntos de sopradores fazem a limpeza dos tubos na altura do superaquecedor e economizador, e efetuam o ciclo de sopragem na região da tremonha. O ciclo de acionamento é de um soprador por dia. A temperatura dos gases na altura da tremonha é em torno de $360^{\circ} \mathrm{C}$. 
As análises para o mapeamento dos problemas associados à formação das cinzas na caldeira foram: determinação da composição química elementar inorgânica e teste de fusão das cinzas. Para a análise química elementar inorgânica foi adotado o procedimento descrito por Henne et al. (2019) e os compostos químicos determinados no espectrofotômetro de emissão óptica com plasma indutivamente acoplado (Perkin Elmer Modelo Optima 8300). Para a conversão de elementos para a forma de óxidos foi utilizada a Norma UNE-EN 15290 (EN, 2011).

O teste do ponto de fusão das cinzas foi realizado no analisador Leitz Wetzlar Germany Ash Fusion Determinator. Foram obtidas as temperaturas de deformação (DT), esfera (ST), semi-esfera (HT) e de fusão (FT). A taxa de aquecimento foi de $10 \mathrm{~K} /$ min até $1500^{\circ} \mathrm{C}$. Os cones de cinzas avaliados tinham espessura de $3 \mathrm{~mm}$ por $3 \mathrm{~mm}$ de altura.

Os índices de deposição foram calculados conforme Pronobis (2005). Para analisar a tendência de escória/incrustação das cinzas foram utilizadas as correlações com forma B/A, onde B agrupa os compostos com baixa temperatura de fusão e $A$ os compostos com maior temperatura de fusão (PRONOBIS, 2005; MASIÁ et al. 2007; NUNES et al., 2019), conforme Equações (1), (2), (3), (4) e (5).

$\mathrm{R}\left(\frac{\mathrm{B}}{\mathrm{A}}\right)=\frac{\mathrm{Fe}_{2} \mathrm{O}_{3}+\mathrm{CaO}+\mathrm{MgO}+\mathrm{K}_{2} \mathrm{O}+\mathrm{Na}_{2} \mathrm{O}}{\mathrm{SiO}_{2}+\mathrm{TiO}_{2}+\mathrm{Al}_{2} \mathrm{O}_{3}}$

Em que: $\mathrm{R}(\mathrm{B} / \mathrm{A})$ = Índice de deposição; $\mathrm{B}$ = Elementos de baixa temperatura de fusão; $\mathrm{A}$

$=$ Elementos de alta temperatura de fusão.

Rs $=(B / A) * S^{d}$

Em que: Rs = Índice de escória; (B/A) = Índice de deposição; $S^{d}=$ Teor de enxofre (\%) base seca.

$\mathrm{F}_{\mathrm{u}}=(\mathrm{B} / \mathrm{A}) *\left(\mathrm{Na}_{2} \mathrm{O}+\mathrm{K}_{2} \mathrm{O}\right)$

Em que: $\mathrm{F}_{\mathrm{u}}=$ Índice de incrustação; (B/A) = Índice de deposição; $\mathrm{Na}_{2} \mathrm{O}$ = Óxidos de sódio; $\mathrm{K}_{2} \mathrm{O}=$ Óxido de potássio. 
$\mathrm{S}_{\mathrm{R}}=\left(\mathrm{SiO}_{2} * 100\right) /\left(\mathrm{SiO}_{2}+\mathrm{MgO}+\mathrm{CaO}+\mathrm{Fe}_{2} \mathrm{O}_{3}\right)$

Em que: $\mathrm{S}_{\mathrm{R}}=$ Taxa de escória ou índice de viscosidade; $\mathrm{SiO}_{2}=$ Óxido de silício; $\mathrm{MgO}=$ Óxido de magnésio; $\mathrm{CaO}=$ Óxido de cálcio; $\mathrm{Fe}_{2} \mathrm{O}_{3}=$ Óxido de ferro.

$\mathrm{Al}=\left(\mathrm{Na}_{2} \mathrm{O}+\mathrm{K}_{2} \mathrm{O}\right) \mathrm{kg} / \mathrm{GJ}$

Em que: $\mathrm{Al}$ =Índice de álcali; $\mathrm{Na}_{2} \mathrm{O}$ = Óxidos de sódio; $\mathrm{K}_{2} \mathrm{O}=$ Óxido de potássio; $\mathrm{Kg} / \mathrm{GJ}=$ massa pela energia do combustível.

O valor do óxido de titânio não foi obtido na análise elementar, sendo utilizado o valor de 0,55\% (MASIÁ et al., 2007). Os teores de enxofre elementar, utilizados para o cálculo do índice de escória, foram obtidos em analisador elementar CHN-S da Perkin Elmer, modelo 2400, segundo procedimento descrito por Henne et al. (2019) (Tabela 2).

Tabela 2 - Teores de enxofre (\% $\left.\mathrm{S}^{\mathrm{d}}\right)$ na base seca das amostras analisadas

\begin{tabular}{ccccccc}
\hline Coleta & Biomassa & Readler & Tremonha & $\begin{array}{c}\text { Lavador } \\
\text { de gases }\end{array}$ & Decantador & $\begin{array}{c}\text { Cinza } \\
\text { da biomassa }\end{array}$ \\
\hline 1 & 0,98 & 0,19 & 0,40 & 0,14 & 0,24 & 0,49 \\
2 & 0,76 & 0,15 & 0,06 & 0,19 & 0,02 & 0,04 \\
3 & 1,02 & 0,07 & 0,24 & 0,34 & 0,06 & 0,03 \\
\hline
\end{tabular}

Fonte: Autores (2021)

Os resultados obtidos nas equações anteriores foram comparados aos valores e critérios estabelecidos por Gupta et al. (1998) (Tabela 3).

Para todas as propriedades analisadas foram obtidas as médias e coeficiente de variação. O delineamento experimental utilizado foi o inteiramente casualisado, onde foi aplicada a ANOVA. Para a análise das variações entre médias foi aplicado o teste de Scott-Knott (5\%). Foi utilizado também o coeficiente de correlação de Pearson ( $r$ ) para estabelecer as correlações lineares entre dois conjuntos de variáveis que potencialmente poderiam ter relação entre si (os índices de deposição e os óxidos). 
Tabela 3 - Parâmetros de classificação da potencialidade de ocorrência dos índices de deposição

\begin{tabular}{lcc}
\hline \multicolumn{1}{c}{ Índice } & Valores limites & Potencialidade de ocorrência \\
\hline & $\mathrm{R}_{\mathrm{S}}<0,6$ & Baixa escória \\
& $\mathrm{R}_{\mathrm{S}} \geq 0,6-2,0$ & Média \\
& $\mathrm{R}_{\mathrm{S}} \geq 2,0-2,6$ & Alta \\
Índice de escória & $\mathrm{R}_{\mathrm{S}} \geq 2,6$ & Extremamente alta \\
\hline & $\mathrm{F}_{\mathrm{u}} \leq 0,6$ & Baixa \\
& $\mathrm{F}_{\mathrm{u}}>0,6-40$ & Alta \\
Índice de incrustação & $\mathrm{F}_{\mathrm{u}} \geq 40$ & Extremamente alta \\
\hline Taxa de escória ou Índice de viscosidade & $\mathrm{S}_{\mathrm{R}}>72$ & Baixa \\
& $72 \geq \mathrm{S}_{\mathrm{R}}>65$ & Alta \\
\hline Índice de álcali & $\mathrm{S}_{\mathrm{R}} \leq 65$ & Provável ocorrência \\
& $0,17<\mathrm{Al}<0,34$ & Ocorre \\
\hline
\end{tabular}

Fonte: Gupta et al. (1998)

\section{RESULTADOS E DISCUSSÕES}

Os óxidos de silício (Si), alumínio (Al), ferro (Fe), cálcio (Ca), potássio (K) e magnésio (Mg), respectivamente, foram os compostos presentes em maior quantidade nas cinzas da biomassa e nas cinzas do readler, tremonha e decantador (Tabela 4). As cinzas do lavador de gases também tiveram os mesmos componentes majoritários, mas em ordem de concentração diferente dos demais pontos de amostragem. Segundo Saidur et al. (2011), as cinzas da madeira têm como elementos majoritários o Ca e o K e baixos teores de Si. As cinzas retidas no gás de combustão formam partículas de cinza volante grossas (que corresponde ao readler), normalmente compostas pelos principais e secundários elementos formadores de biomassa: $\mathrm{Ca}, \mathrm{Mg}, \mathrm{Si}, \mathrm{K}, \mathrm{Al}$ e algum material orgânico não queimado (VASSILEV et al., 2013). Dentro do gás de 
combustão, a condensação de elementos gasosos de $\mathrm{K}, \mathrm{Na}, \mathrm{S}, \mathrm{Cl}$ e oligoelementos (TEs) ocorre nessas partículas de cinza arrastadas (cinzas leves, que correspondem à tremonha, decantador e lavador de gases). Ao mesmo tempo, aerossóis são liberados do combustível e a nucleação combinada com condensação de álcali e TEs ocorre com os aerossóis para produzir partículas finas (VAN LOO, KOPPEJAN, 2008).

Nas amostras foram encontradas elevadas concentrações de Si, Fe e Al, o que confirma a presença de contaminantes da biomassa por agentes externos como terra, areia e pedras. A presença de $\mathrm{SiO}_{2}$ e $\mathrm{Al}_{2} \mathrm{O}_{3}$ pode ser justificada pela contaminação ocorrida durante as operações florestais, como corte de árvores, onde normalmente as toras são arrastadas pelo solo (KEEFE et al., 2014). A contaminação com terra, pedras e outros agentes inorgânicos influencia a composição química elementar das cinzas. Esses contaminantes reagem com o combustível por meio de ligações químicas, se comportando como catalizadores nas variações observadas na operação dos sistemas de combustão.

Na literatura, os valores apresentados por Masiá et al. (2007) (Tabela 5) foram os mais próximos dos observados para as cinzas de biomassa de cavacos de pinus analisadas neste trabalho. Neste trabalho, o teor de óxido de sódio foi muito inferior ao relatado pelo autor supracitado, que foi de 1,19\%. Teores elevados de óxido de sódio contribuem para a formação de escória, incrustações e formação de álcali na caldeira. Nunes et al. (2019) constataram que a elevada probabilidade de escória e incrustação, quando se utilizam cavacos de madeira de Pinus pinaster não descascados como combustível em caldeira, foi provocada principalmente por metais alcalinos, cujos valores foram muito superiores no trabalho desses autores em comparação aos observados aqui. 
Para o óxido de silício, as maiores concentrações foram observadas nas cinzas da biomassa que representam a matéria-prima que está entrando na caldeira e no readler. O readler, que é o primeiro ponto de recolhimento das cinzas, e juntamente com elas são coletados materiais que sofreram combustão parcial. Esses dois pontos foram estatisticamente semelhantes, pelo teste de médias, para este composto químico. Para o óxido de alumínio, os pontos que tiveram concentrações semelhantes foram o readler e o decantador, onde ficam retiradas partículas de cinzas de maior granulometria. As concentrações de óxido de ferro, potássio e magnésio foram diferentes entre todos os pontos de coleta.

Tabela 4 - Composição elementar inorgânica (\%) na forma de óxidos das amostras de cinzas

\begin{tabular}{|c|c|c|c|c|c|c|c|c|c|}
\hline \multirow{2}{*}{$\begin{array}{c}\text { Óxidos } \\
\text { (\%) }\end{array}$} & \multirow[b]{2}{*}{$\mathrm{CP}^{1}$} & \multirow[b]{2}{*}{$\mathrm{CP}^{2}$} & \multirow[b]{2}{*}{$\mathrm{CP}^{3}$} & \multicolumn{6}{|c|}{ Pontos de coleta } \\
\hline & & & & $\begin{array}{l}\text { Cinza da } \\
\text { Biomassa }\end{array}$ & Readler & Tremonha & $\begin{array}{l}\text { Lavador } \\
\text { de gases }\end{array}$ & Decantador & CV \\
\hline $\mathrm{Al}_{2} \mathrm{O}_{3}$ & 4,60 & 7,00 & $10,96-18,33$ & $9,40 \mathrm{a}$ & $7,22 b$ & $2,32 \mathrm{c}$ & $0,39 d$ & $7,23 \mathrm{~b}$ & 18,03 \\
\hline $\mathrm{CaO}$ & 25,70 & 7,85 & $1,82-9,23$ & $6,50 \mathrm{a}$ & $3,28 \mathrm{~b}$ & $0,97 c$ & $0,59 c$ & $3,90 \mathrm{~b}$ & 23,44 \\
\hline $\mathrm{Cr}_{2} \mathrm{O}_{3}$ & - & n.a. & & $0,036 a$ & $0,008 \mathrm{~b}$ & $0,002 \mathrm{c}$ & $0,000 \mathrm{c}$ & $0,006 \mathrm{~b}$ & 43,36 \\
\hline $\mathrm{CuO}$ & - & - & & $0,033 a$ & $0,009 \mathrm{~b}$ & $0,002 \mathrm{c}$ & $0,003 \mathrm{c}$ & $0,009 \mathrm{~b}$ & 37,49 \\
\hline $\mathrm{Fe}_{2} \mathrm{O}_{3}$ & 2,90 & 5,42 & $7,29-41,43$ & $7,23 a$ & $6,32 \mathrm{~b}$ & $1,88 d$ & $0,16 \mathrm{e}$ & $4,76 \mathrm{c}$ & 20,82 \\
\hline $\mathrm{K}_{2} \mathrm{O}$ & 8,20 & 4,49 & $4,58-10,30$ & $3,62 \mathrm{a}$ & $2,69 \mathrm{~b}$ & $0,82 d$ & $0,28 \mathrm{e}$ & $2,19 \mathrm{c}$ & 21,11 \\
\hline $\mathrm{MgO}$ & 3,60 & 2,42 & $6,30-12,44$ & $2,56 \mathrm{a}$ & $1,58 b$ & $0,41 \mathrm{c}$ & $0,26 c$ & $1,44 b$ & 25,22 \\
\hline $\mathrm{MnO}$ & & - & $0-1,15$ & $0,79 a$ & $0,40 \mathrm{~b}$ & $0,10 \mathrm{c}$ & $0,05 c$ & $0,47 b$ & 20,44 \\
\hline $\mathrm{Na}_{2} \mathrm{O}$ & 0,60 & 1,19 & $3,17-4,71$ & $0,000 \mathrm{a}$ & $0,000 \mathrm{a}$ & $0,000 \mathrm{a}$ & $0,0004 a$ & $0,000 a$ & - \\
\hline $\mathrm{PbO}$ & - & - & & $0,0004 a$ & $0,0006 a$ & $0,0004 \mathrm{a}$ & $0,0001 \mathrm{a}$ & 0,0007 a & - \\
\hline $\mathrm{ZnO}$ & - & 0,12 & & $0,035 a$ & $0,002 b$ & $0,008 \mathrm{~b}$ & $0,004 b$ & $0,032 a$ & 57,69 \\
\hline $\mathrm{P}_{2} \mathrm{O}_{5}$ & 3,40 & 0,65 & $0,91-1,23$ & $1,71 \mathrm{a}$ & $0,67 \mathrm{c}$ & $0,21 d$ & $0,06 d$ & $1,12 b$ & 23,55 \\
\hline $\mathrm{SiO}_{2}$ & 45,80 & 67,84 & $10,91-45,63$ & $58,22 \mathrm{a}$ & 50,91 a & $12,71 \mathrm{~b}$ & $7,09 \mathrm{~b}$ & $18,63 \mathrm{~b}$ & 36,92 \\
\hline
\end{tabular}

Fonte: Autores (2021)

Em que: CP = cavaco de Pinus; ${ }^{1}$ Nunes et al. (2016); ${ }^{2}$ Masiá et al. (2007); ${ }^{3}$ Nunes et al. (2019) CV = coeficiente de variação. Médias seguidas da mesma letra, na linha, são iguais estatisticamente segundo Scott Knott, a um nível de probabilidade de $95 \%$. 
Os valores de temperatura de esfera (ST), temperatura de semi-esfera (HT) e temperatura de fusão (FT) foram superiores neste trabalho em comparação com os valores de Rizvi et al. (2015), provavelmente devido a diferença na presença e formação de hidroxilas. Esses grupos funcionais são responsáveis pelas formações de cristais em altas temperaturas (Tabela 5).

Tabela 5 - Comparação das temperaturas de fusão das cinzas das amostras analisadas com a literatura

\begin{tabular}{lcccc}
\hline \multicolumn{1}{c}{ Material } & DT $\left({ }^{\circ} \mathbf{C}\right)$ & ST $\left({ }^{\circ} \mathbf{C}\right)$ & HT $\left({ }^{\circ} \mathbf{C}\right)$ & FT $\left({ }^{\circ} \mathbf{C}\right)$ \\
\hline Madeira $(\text { Pinus })^{1}$ & - & 1095 & 1210 & 1235 \\
Cinza da biomassa & 1230 & 1234 & 1240 & 1261 \\
Readler & 1225 & 1245 & 1282 & 1330 \\
Tremonha & 1272 & 1272 & 1282 & 1385 \\
Lavador de gases & 1208 & 1218 & 1237 & 1302 \\
Decantador & 1233 & 1238 & 1249 & 1283 \\
\hline
\end{tabular}

Fonte: Autores (2021)

Em que: $\mathrm{DT}=$ Temperatura de deformação $\left({ }^{\circ} \mathrm{C}\right) ; \mathrm{ST}=$ Temperatura de esfera $\left({ }^{\circ} \mathrm{C}\right) ; \mathrm{HT}=$ Temperatura de semi-esfera $\left({ }^{\circ} \mathrm{C}\right) ; \mathrm{FT}=$ Temperatura de fusão $\left({ }^{\circ} \mathrm{C}\right)$. Os resultados de temperatura correspondem à média de dois ou mais ensaios e estão de acordo com os limites de repetitividade estabelecidos na norma DIN 51730. 'Referência de testes de temperaturas de fusão para madeira de Pinus (Fonte: Rizvi et al., 2015).

As temperaturas de fusão foram elevadas em todos os pontos de amostragem. A faixa de temperatura onde ocorreu a fusão (FT) das cinzas em todas as amostras ficou entre $1261^{\circ} \mathrm{C}$ e $1385^{\circ} \mathrm{C}$. Isso demonstra que foi pequena a diferença de temperatura do ponto de fusão entre todas as amostras avaliadas. Essas elevadas temperaturas de fusão reduzem também o risco de ocorrência de problemas associados à combustão da biomassa florestal na caldeira.

Os elementos Cl, K, Si, Ca e P não podem ser avaliados individualmente, devido a interações complexas entre cada elemento. Assim, de forma isolada eles não explicam as temperaturas de fusão e formações de deposições. Na avaliação se devem incluir as interações entre diferentes óxidos e o equilíbrio dessas composições. Além disso, 
esses fatores são extremamente dependentes do tipo de biomassa e das condições operacionais (PISA; LAZAROIU, 2012).

As temperaturas de fusão estão ligadas à presença dos elementos que constituem a formação de compostos inorgânicos como $\mathrm{KAISi}_{2} \mathrm{O}_{6}\left(\mathrm{~S}_{2}\right), \mathrm{Ca}_{2} \mathrm{MgSi}_{2} \mathrm{O}_{7}(\mathrm{~S})$, $\mathrm{Ca}_{3} \mathrm{Fe}_{2} \mathrm{Si}_{2} \mathrm{O}_{12}(\mathrm{~S})$ nas cinzas. Esses conjuntos de elementos são responsáveis pela faixa de temperatura de fusão entre $1.100^{\circ} \mathrm{C}$ e $1.300^{\circ} \mathrm{C}$. Acima dessa faixa de temperatura ocorrem processos de descarbonização e deshidroxilização, que causam quebras de estruturas de cristais em altas temperaturas (RIZVI et al., 2015).

O elevado teor de óxido de silício no readler, aliado a quantidade reduzida de enxofre, reduziu a temperatura de fusão neste ponto de amostragem. A consequência desse fato é o desmoronamento das estruturas na fase de fusão. O óxido de silício forma ligações mais isoladas e distribuídas em associação com outros componentes, causando a fragilização das ligações, reduzindo a temperatura de fusão. A temperatura de fusão do silício é de $1.414^{\circ} \mathrm{C}$.

Na tremonha, a cinza teve a maior temperatura de fusão, devido à distribuição da cadeia na formação de compostos complexos com Al, Ca, Fe, K, Mg, e reduzidas quantidades de P, Si e S. Já no lavador de gases, o que predominou na composição química elementar foi o óxido de silício em relação aos demais componentes, podendo estar associado a ligações menos complexas $\mathrm{CaMgSi}_{2} \mathrm{O}_{6}(\mathrm{~S}), \mathrm{CaSiO}_{3}(\mathrm{~S}), \mathrm{Ca}_{3} \mathrm{Al}_{2} \mathrm{Si}_{3} \mathrm{O}_{12}(\mathrm{~S})$ em comparação com as amostras de temperaturas de fusão superiores.

No decantador ocorreu a formação de elementos com menor estabilidade, como o $\mathrm{Ca}_{3} \mathrm{Fe}_{2} \mathrm{Si}_{3} \mathrm{O}_{12}(\mathrm{~S})$ com menores proporções de $\mathrm{CaMgSi}_{2} \mathrm{O}_{6}(\mathrm{~S})$, e $\mathrm{CaSiO}_{3}(\mathrm{~S})$. Isso contribuiu para a diminuição da temperatura de fusão das cinzas neste local. Já as cinzas de biomassa, por possuírem maiores concentrações de óxidos em comparação com as demais amostras, ocorreram formações com menores temperaturas de fusão, como $\mathrm{CaMgSi}_{2} \mathrm{O}_{6}(\mathrm{~S})$, e também parcelas de $\mathrm{CaSiO}_{3}(\mathrm{~S})$, que contribuíram para temperaturas do ponto de fusão menores que $1.300^{\circ} \mathrm{C}$.

Apesar das elevadas temperaturas de fusão registradas contribuírem para 
a redução de problemas de combustão da biomassa na caldeira, a formação de aglomeração, de deposição e formação de pedras pode ocorrer por alterações nos parâmetros de operação da usina. Quando as chamas alcançam camadas mais altas acima da grelha, ocorre o aumento da temperatura em faixas próximas da temperatura de fusão das cinzas da biomassa e das cinzas na saída dos gases da fornalha (1200 a $\left.1300^{\circ} \mathrm{C}\right)$, na região da tremonha.

Portanto, na tremonha pode-se chegar às temperaturas que provocam a fusão dessas cinzas, provocando entupimento dos tubos de passagem dos gases da combustão. Esse fenômeno é observado quando a usina opera com carga máxima. Nessas condições ocorrem pequenos distúrbios de queima e oscilação de processo, gerando mais ou menos gás, levando a aumentar ou diminuir a tiragem, deslocando a chama para frente ou para trás do ponto de combustão, na câmara de combustão.

Os índices de deposição (R, Rs, Fu e Sr) tiveram valores similares aos publicados por Masiá et al. (2007), mas distintos dos obtidos por Nunes et al. (2019), para o mesmo tipo de biomassa analisada (Tabela 6). O índice de deposição (R (B/A)) apresentou variação entre o lavador de gases e os demais pontos de amostragem. Isso ocorreu devido às baixas concentrações de óxido de ferro, alumínio e sílica neste ponto. Deposições podem gerar áreas de incrustação e corrosão que irão acelerar o desgaste das superfícies de transferência de calor e até mesmo da estrutura da caldeira (VASSILEV et al., 2012).

Os índices de escória (Rs) não variaram estatisticamente entre os pontos de amostragem. O potencial de escória foi baixo em todos os locais de coleta das cinzas e para a biomassa. A formação de grandes áreas de escória nas superfícies de troca térmica das caldeiras provoca redução da eficiência de transferência de calor o funcionamento irregular do equipamento (VASSILEV et al., 2012).

Os valores de Índice de incrustação (Fu) da cinza de biomassa e do readler foram iguais (Alto potencial). No lavador de gases e na tremonha os índices foram estatisticamente iguais (Baixo potencial de incrustação). As cinzas da biomassa, do 
decantador e do readler, com alto potencial de incrustação, foram as cinzas com maiores teores de óxido de potássio. O potássio está ligado organicamente na biomassa, vaporizando e se decompondo durante a combustão, formando cloretos óxidos, sulfatos e hidróxidos. Esses compostos têm baixa temperatura de fusão e por isso são condensados nas paredes, tubos e juntamente com partículas de cinzas volantes causam incrustações e escórias (MILES et al., 1996).

Tabela 6 - Comparativo dos valores de deposição para os valores obtidos neste trabalho com a literatura

\begin{tabular}{|c|c|c|c|c|c|c|c|c|c|}
\hline \multirow{2}{*}{$\begin{array}{l}\text { Amostras/ Índices } \\
\text { Masiá et al. (2007) }\end{array}$} & \multirow{2}{*}{$\begin{array}{c}\mathbf{R}(\mathbf{B} / \mathbf{A}) \\
0,280\end{array}$} & \multicolumn{2}{|l|}{ RS } & \multicolumn{2}{|l|}{$\mathrm{Fu}$} & \multicolumn{2}{|l|}{ Sr } & \multicolumn{2}{|l|}{ Al } \\
\hline & & 0,020 & B & 1,610 & $A$ & 81,22 & B & 0,170 & $P$ \\
\hline Nunes et al. (2019) ${ }^{1}$ & & $0,46-2,06$ & B-A & $3,59-27,30$ & $A$ & & & $0,11-0,21$ & NP-P \\
\hline Cinzas de Biomassa & $0,283 a$ & $0,066 a$ & B & $1,050 \mathrm{a}$ & $A$ & $78,80 \mathrm{~b}$ & B & $010 h$ & $P$ \\
\hline Readler & 0,399 a & $0,053 a$ & B & $1,110 a$ & $A$ & 70,94 b & M & $1,170 \mathrm{a}$ & $P$ \\
\hline Tremonha & $0,256 a$ & $0,009 a$ & B & $0,270 \mathrm{c}$ & $\mathrm{B}$ & $81,44 \mathrm{~b}$ & $\sigma$ & $0,040 \mathrm{c}$ & Não \\
\hline Lavador de Gás & $0,062 \mathrm{~b}$ & $0,010 a$ & B & $0,016 \mathrm{c}$ & $\mathrm{B}$ & $95,17 \mathrm{a}$ & B & $0,009 \mathrm{c}$ & Não \\
\hline Decantador & $0,312 \mathrm{a}$ & $0,041 \mathrm{a}$ & B & $0,690 \mathrm{~b}$ & $A$ & $76,06 \mathrm{~b}$ & $B$ & $0,150 \mathrm{~b}$ & Não \\
\hline
\end{tabular}

Fonte: Autores (2021)

Em que: ${ }^{1}$ Cinzas de Cavaco de Pinus. $B=$ Baixa; $M=$ Média; $A=A l t a ; ~ P=$ provável; $R(B / A)=$ Deposição; Rs = Escória; $\mathrm{Fu}=$ Incrustação; $\mathrm{Sr}=$ Viscosidade; $\mathrm{Al}=$ Álcali. Médias seguidas da mesma letra são iguais estatisticamente segundo Skott Knott, a um nível de probabilidade de 95\%.

Os fenômenos de incrustação e escória em caldeiras são responsáveis por um maior número de paradas técnicas dos equipamentos e por aumento nos custos de manutenção (NUNES et al., 2019). Neste estudo foi possível constatar que o potássio teve influência sobre o índice de incrustação. A temperatura de fusão para esses locais também foi menor em comparação com a tremonha. Com relação ao Índice de incrustação (Fu), o alto valor observado para a biomassa pode provocar entupimento junto às passagens de gases, devido ao arraste das cinzas. No readler e decantador podem ocorrer acúmulo de materiais e entupimento nas tubulações de condução de água. 
No índice de viscosidade (Sr), o maior valor do lavador de gases foi estatisticamente diferente dos demais pontos de amostragem. A classificação dos índices demonstrou que o readler, com o menor valor, tem potencial de viscosidade médio, comparativamente com os outros pontos que têm baixo potencial. Esse índice no readler é importante, pois com a viscosidade pode ocorrer aglomeração dos elementos gerando pedras e causando falha na limpeza da grelha.

O índice de Álcali (Al) do readler foi o maior valor registrado, sendo diferente dos demais e apresentando provável ocorrência de corrosão. A saída das cinzas no readler exige manutenções frequentes devido à formação de produtos, tanto básicos como ácidos, nesse ponto. Isso resulta na vulnerabilidade quanto à corrosão das peças. As cinzas da biomassa apresentam potencial para a produção de álcali, e consequente ocorrência de corrosão. Na tremonha, lavador de gases e decantador o risco de corrosão é nulo. No decantador e lavador de gases é importante que não haja a formação de álcalis, pois isso contribui para a corrosão de alguns tipos de metais que compõe esses equipamentos.

A composição química elementar do combustível sozinha não pode ser utilizada como indicador de deposição absoluta, porque a escória e incrustação também dependem da disposição construtiva e operação da caldeira e dos parâmetros de temperaturas e vazão de ar (MILES et al., 1996). Ocorreram alterações em alguns parâmetros de operação da caldeira entre as três coletas (Tabela 1). Aliado as informações dos gestores e operadores da termelétrica foi possível constatar que as variações mais importantes no período de estudos foram: (a) o aumento da produção de vapor foi diretamente relacionado ao consumo de biomassa; (b) o ar secundário aumentou a pressão de alimentação, resultando em aumento na vazão de entrada de ar na caldeira; (c) houve variações na temperatura dos gases no pré-ar secundário; (d) o aumento da vazão dos gases na saída do economizador resultou no aumento da pressão de saída dos gases no economizador; (e) ocorreram variações nas temperaturas de combustão, principalmente na altura da tremonha e lavador de gases. 
Essas variações operacionais tiveram influência sobre as propriedades das cinzas nos pontos de amostragem, na produção de energia elétrica e de vapor. A variações foram tanto nas propriedades quanto na quantidade de cinzas produzidas nos pontos de amostragem. O aumento da quantidade de cinzas se deu pelo arraste, devido ao aumento do volume de circulação de ar e gases.

Com relação aos problemas observados pelos gestores e operadores da usina, os relatados como mais frequentes e importantes estiveram relacionados à:

1 - Formação de pedras (readler): este problema ocorre no momento da limpeza das grelhas, quando são abertas para a passagem das cinzas e sua extração. Há casos em que ocorre a formação de pedras grandes, que acabam impedindo o fechamento das grelhas, provocando paradas para manutenção na seção. Além do tamanho, o número de pedras formadas foi outra preocupação;

2 - Entupimento (tremonha): neste ponto ocorre entupimento no descarte das cinzas. Para solucionar o problema, a medida adotada foi o aumento do diâmetro de passagem do duto. Esse procedimento facilitou a passagem das cinzas. A saída da fornalha, na altura da tremonha, nos superaquecedores, onde se formam pedras são os pontos onde há o maior nível de entupimento por incrustações e deposição;

3 - Diminuição da espessura das paredes dos tubos de fora para dentro (economizador). Esse problema é sempre detectado durante a manutenção anual da caldeira. Quando isso ocorre, é feita a substituição dos tubos e curvas do economizador;

4 - Corrosão: não é realizado o controle das taxas de corrosão. No entanto, as correções são acompanhadas por meio de inspeções anuais e corrigidos os problemas com a substituição de tubos do pré-ar;

5 - Durante 14 anos de operação da usina as paredes da fornalha não tiveram problemas.

Assim, com base nos resultados obtidos nos índices de deposição (R, Rs, Fu, Sr e Al) e nos relatos dos gestores e operadores da usina é possível afirmar que, nas grelhas, a formação de aglomerados (pedras) ocorre pela associação dos elementos químicos 
presentes na biomassa e das temperaturas de fusão desses elementos. O conjunto de grelhas são formados por 6 seções. Essas seções são abertas em intervalos de quatro horas, uma de cada vez, de forma independente. Para a realização da limpeza, a alimentação da biomassa é suspensa na seção até que haja a diminuição da altura do leito de biomassa e os resíduos possam ser retirados por meio da abertura das aletas das grelhas.

Esse procedimento é realizado para que ocorra a queima da biomassa restante sobre a grelha. Esse fato gera a concentração dos compostos minerais e os expõe a temperaturas mais elevadas, permitindo que as cinzas atinjam a temperatura de fusão destas combinações de materiais, propiciando a formação de aglomerados (pedras). Quando ocorre a abertura das aletas da grelha, para e remoção das cinzas, essas pedras formadas ficam entre as aletas, impedindo a abertura e fechamento do sistema. As pedras podem ser formadas na superfície das camadas de cavacos na seção da grelha que está sendo limpa. Essa camada fica exposta aos compostos minerais aglutinantes, provocando a formação das pedras.

Depois da operação de limpeza, inicia-se novo processo de alimentação de cavacos sobre a grelha, formando uma nova camada. Esse procedimento provoca a redução da temperatura, fazendo com que os produtos aglutinados se solidifiquem, formando os aglomerados (pedras), com temperaturas entre $1261^{\circ} \mathrm{C}$ à $1385^{\circ} \mathrm{C}$.

As grelhas são refrigeradas com o ar primário e em alguns casos com vapor de limpeza. Se o vapor de limpeza das grelhas for saturado, é importante acompanhar o título do vapor. O vapor aumenta a umidade no ambiente, o que também pode contribuir para a formação dos aglomerados. Além disso, tanto a umidade da biomassa, quanto a umidade do vapor podem formar bolhas que penetram nos refratários que são porosos. As variações de temperatura provocam pressão interna nos refratários, podendo provocar rupturas das camadas de refratário, que protegem as paredes da fornalha. 
Na tremonha passam as cinzas volantes maiores e mais pesadas. Essas partículas podem se concentrar, devido à gravidade, nos primeiros pontos de coleta das cinzas, na saída dos gases da câmara de combustão. As cinzas com menor granulometria (leves) seguem o fluxo do gás, passando pelo pré-ar, sendo que parte delas pode ficar alojada neste ponto, e o restante segue para o lavador de gases. As cinzas mais leves e finas são sequestradas pelo lavador de gás e coletadas pelo anel hidráulico, sendo direcionadas para o decantador, que retém as partículas residuais.

Para realizar uma avaliação mais acurada nos locais onde podem ocorrer deposições, é imprescindível a identificação dos locais onde esses problemas podem potencialmente ocorrer. Após a identificação desses locais, devem-se realizar coletas de amostras nestes pontos e avaliar a composição química elementar das cinzas, e os índices de deposição devem ser calculados para mapear com maior precisão a formação desses problemas.

Para a determinação da formação de incrustações é importante a determinação do alcance da altura das chamas. A altura das chamas tem interferência direta na exposição das partículas de cinzas a altas temperaturas, principalmente na altura do superaquecedor, seguida da tremonha. Se nesses locais as cinzas atingirem a temperatura de fusão, seguida da redução da temperatura, as partículas se solidificam, formando incrustações. O ajuste da vazão do ar secundário influencia o alcance das chamas. Além disso, a qualidade do ar primário e secundário são importantes, tanto em função da temperatura quanto pela umidade que entra na fornalha. Maior quantidade de umidade requer mais energia para a secagem da biomassa e do ar, afetando a eficiência da caldeira.

A limpeza por sopragem com vapor saturado também é utilizada para a remoção mecânica de uma parcela das cinzas. No entanto, a quantidade de umidade injetada no sistema, aliada aos compostos formados pelos elementos químicos das cinzas podem causar escória e deposições. Esse fenômeno explica a corrosão que ocorre da parte externa para a parte interna dos tubos, observada pelos colaboradores da 
termelétrica analisada. O controle desses desgastes por medições de espessura de tubos nas inspeções é um ponto importante para mapear este fenômeno ao longo da vida da caldeira.

A coleta de amostras de cinzas, obtenção de imagens por fotos e análises químicas das peças, substituídas durante as paradas das caldeiras para manutenção e limpeza, devem ser uma prática a ser adotada pelas empresas, para a obtenção de informações acerca dos problemas associados às cinzas. Essas atividades permitem, além identificação dos problemas de deposição, a realização de ajustes nos parâmetros de operação da caldeira. Outro ponto que não foi considerado neste estudo, mas que pode trazer informações valiosas sobre o efeito nas cinzas na operação da usina é na saída dos gases da chaminé.

A variação do perfil de temperatura ao longo da passagem dos gases que arrastam as cinzas é influenciada pelas alterações de capacidade de produção, que por consequência interferem nas vazões de ar e gases na caldeira. A distribuição de cinzas ao longo do processo está ligada à dinâmica dos gases em relação aos parâmetros de processo (temperatura, pressão e pontos de passagem das cinzas dentro do equipamento). Esses fatores, juntamente com a gravidade, determinam a forma de circulação das cinzas pelos dutos e passagens até os locais de coleta para o tratamento das cinzas.

O aumento da capacidade de geração de energia térmica afeta a circulação de água e ar nas tubulações, afetando também a temperatura dos gases no momento das transferências de calor economizador e pré-ar. O perfil de distribuição dos gases pode ser tanto longitudinal quanto transversal. E, no caso da ocorrência de deposições por escória, podem ocorrer fluxos preferenciais dos gases. Isso também resulta em redução de eficiência nas trocas de calor, além de causar arraste de energia térmica para fora do sistema. Portanto, é fundamental o conhecimento da temperatura dos gases na câmera de combustão e nas regiões da tremonha, pré-ar, lavador de gases e chaminé. 
As propriedades físicas e energéticas da biomassa também interferem na regularidade de queima dentro da fornalha, propiciando uma transferência de calor bem distribuída, melhorando a tiragem dos gases de combustão o e desempenho de manipulação das grelhas.

As correções mais fortes e positivas com a deposição (R) foram com o $\mathrm{Fe}_{2} \mathrm{O}_{3^{\prime}}$ $\mathrm{Al}_{2} \mathrm{O}_{3}$, e $\mathrm{K}_{2} \mathrm{O}$, seguida de uma correlação positiva, mas menos intensa com o $\mathrm{MgO}$ e $\mathrm{CaO}$ (Tabela 7). A deposição é influenciada de forma negativa e com nível de correlação baixo pela presença de $\mathrm{SiO}_{2}$ e $\mathrm{NaO}_{2}$. Assim, o $\mathrm{Fe}_{2} \mathrm{O}_{3}$ foi o composto químico mais importante para a deposição.

Tabela 7 - Correlações entre os compostos químicos inorgânicos gerados na combustão da biomassa e os índices de deposição

\begin{tabular}{cccccc}
\hline & $\mathbf{R}(\mathbf{B} / \mathbf{A})$ & $\mathbf{R S}$ & $\mathbf{F u}$ & $\mathbf{S r}$ & Al \\
\hline $\mathrm{Al}_{2} \mathrm{O}_{3}$ & 0,53 & 0,22 & 0,85 & & \\
$\mathrm{CaO}$ & 0,39 & 0,18 & 0,75 & $-0,42$ & \\
$\mathrm{Fe}_{2} \mathrm{O}_{3}$ & 0,59 & 0,24 & 0,86 & $-0,61$ & \\
$\mathrm{~K}_{2} \mathrm{O}$ & 0,52 & 0,26 & 0,88 & & 0,41 \\
$\mathrm{MgO}$ & 0,46 & 0,26 & 0,84 & $-0,48$ & \\
$\mathrm{NaO}_{2}$ & $-0,19$ & $-0,08$ & $-0,17$ & & $-0,10$ \\
$\mathrm{SiO}_{2}$ & $-0,40$ & $-0,41$ & $-0,02$ & 0,40 & \\
$\mathrm{~S}$ & & 0,72 & & & \\
\hline
\end{tabular}

Fonte: Autores (2021)

Em que: $\mathrm{R}(\mathrm{B} / \mathrm{A})$ = Deposição; RS = Escória; Fu = Incrustação; Sr = Viscosidade; $\mathrm{Al}$ = Álcali.

$\mathrm{O}$ índice de escória teve correlação positiva e baixa com $\mathrm{K}_{2} \mathrm{O}, \mathrm{MgO}, \mathrm{Fe}_{2} \mathrm{O}_{3^{\prime}} \mathrm{Al}_{2} \mathrm{O}_{3} \mathrm{e}$ $\mathrm{CaO}$ e positiva e alta apenas com o enxofre. O índice de escória apresentou correlação negativa mais alta com o $\mathrm{SiO}_{2}$. Portanto, para a escória, o enxofre foi o elemento mais importante. Quanto ao índice de incrustação, os compostos $\mathrm{Al}_{2} \mathrm{O}_{3}, \mathrm{Fe}_{2} \mathrm{O}_{3}, \mathrm{~K}_{2} \mathrm{O}$ e $\mathrm{MgO}$ apresentaram correlação forte e positiva, sendo o CaO menos expressivo. Assim, para a incrustação, os compostos: $\mathrm{K}_{2} \mathrm{O}, \mathrm{Fe}_{2} \mathrm{O}_{3^{\prime}} \mathrm{Al}_{2} \mathrm{O}_{3}$ e $\mathrm{MgO}$ tiveram importância similar e elevada. Para o índice de viscosidade, o $\mathrm{Fe}_{2} \mathrm{O}_{3}$ apresentou a correlação mais elevada e 
negativa, sendo o composto com maior influência sobre este índice. Também foram negativas as correlações com os $\mathrm{CaO}$ e $\mathrm{MgO}$. A única correlação positiva foi com o $\mathrm{SiO}_{2}$. O índice de Álcali esteve correlacionado, positivamente, com o $\mathrm{K}_{2} \mathrm{Oe}$ de forma negativa e menos expressiva com o $\mathrm{NaO}_{2}$.

\section{CONCLUSÕES}

Os compostos químicos presentes em maior proporção, tanto nos cavacos de madeira, como nas cinzas coletadas em vários locais de amostragem dentro da caldeira foram os óxidos silício, alumínio, ferro, cálcio, potássio e magnésio. A presença de altas porcentagens de óxido de silício, ferro e alumínio confirmam a contaminação da biomassa por agentes externos, como terra, areia e pedras.

A temperatura de fusão das cinzas foi alta em todos os pontos de amostragem, reduzindo a probabilidade de ocorrência de problemas derivados da deposição das cinzas na caldeira. No entanto, as oscilações observadas nos parâmetros de operação da usina aumentaram o potencial de ocorrência de problemas associados à queima da biomassa.

O mapeamento dos problemas relacionados à queima da biomassa em caldeira e a formação das cinzas resultou em baixos riscos de formação de escória. O readler apresentou médio potencial de viscosidade e risco de formação de álcali e juntamente com o decantador apresentou alto potencial de incrustação. Os cálculos dos índices de deposição, obtidos em função da composição química elementar inorgânicas das cinzas, foram capazes de expressar a realidade dos problemas que ocorrem na combustão da biomassa florestal em caldeira, relatados pelos gestores da usina.

Para o potencial de deposição (R) e para o índice de viscosidade, o composto mais importante foi o óxido de ferro; para o índice de escória, o elemento mais importante foi o enxofre; para o índice de incrustação, os compostos: óxido de potássio, óxido de ferro, óxido de alumínio e óxido de magnésio tiveram igual e elevada importância; o índice de Álcali foi mais influenciado pela presença do óxido de potássio. 
De forma geral, os problemas associados à combustão da biomassa em caldeiras de grande porte variam nos diferentes pontos de transporte e de tratamento das cinzas. As condições de operação da caldeira têm importante influência nas alterações da temperatura de fusão das cinzas e agravamento dos problemas relacionados aos índices de deposição.

\section{AGRADECIMENTOS}

Ao Conselho Nacional de Desenvolvimento Científico e Tecnológico (CNPq Processo 311022/2020-0 - PQ 2020), à Fundação de Amparo à Pesquisa e Inovação do Estado de Santa Catarina (FAPESC) pelo apoio financeiro e à Empresa ENGIE BRASIL ENERGIA S.A pelo fornecimento das amostras e das informações de operação da Unidade Termelétrica à Biomassa de Lages, SC.

\section{REFERÊNCIAS}

ABRAHAM, R. et al. Physicochemical characterization and possible applications of the waste biomass ash from oleoresin industries of India. Fuel, Rhode Island, v. 109, p. 366-372, 2013.

CAPEHART, B. L.; TURNER, W. C.; KENNEDY, W. J. Guide to energy management, 5th ed, Lilburn: The Fairmont Press, 2005. 509 p.

CHERNEY, J. H.; VERMA, V. K. Grass pellet Quality Index: A tool to evaluate suitability of grass pellets for small scale combustion systems. Applied energy, Västerås, v. 103, p. 679-684, 2013.

EUROPEAN COMMITTEE FORSTANDARDIZATION. CEN-COMITÉEUROPEO DENORMALIZACIÓN. UNE-EN 15290:Biocombustibles sólidos -Determinación de elementos mayoritarios - Al, Ca, Fe, Mg, P, K, Si, Na y Ti. Bruxelles, 2011, 20 p.

GUPTA, R. P. et al. Computer-controlled scanning electron microscopy of minerals in coalimplications for ash deposition. Progress in Energy and Combustion Science, California, v. 24, n. 6, p. 523-543, 1998.

HENNE, R. A. et al. Characterization of ashes from forest biomass combustion in boilers: a systemic view of potential applications. Floresta, Curitiba, v. 50, n. 1, p. 1081-1090, 2019.

KEEFE, R. et al. Woody biomass logistics. In: KARLEN, Douglas L. (Ed.): Cellulosic energy cropping systems. Blackwell: John Wiley \& Sons, p. 251-279, 2014.

LAMBERG, H. et al. Fine particle and gaseous emissions from a small-scale boiler fueled by pellets of various raw materials. Energy \& Fuels, Washington, v. 27, n. 11, p. 7044-7053, 2013. 
MASIÁ, A. A. T. et al. Characterising ash of biomass and waste. Fuel Processing Technology, Western Australia, v. 88, n. 11-12, p. 1071-1081, 2007.

MILES, T. R. et al. Boiler deposits from firing biomass fuels. Biomass and bioenergy, Birmingham, v. 10, n. 2-3, p. 125-138, 1996.

NUNES, L. J. et al. Evaluation of the utilization of woodchips as fuel for industrial boilers. Journal of cleaner production, Brno, v. 223, p. 270-277, 2019.

NUNES, L. J. R.; MATIAS, J. C. O.; CATALÃO, J. P. S. Biomass combustion systems: a review on the physical and chemical properties of the ashes. Renewable and Sustainable Energy Reviews, Belfast, v. 53, p. 235-242, 2016.

PISA, I.; LAZAROIU, G. Influence of co-combustion of coal/biomass on the corrosion. Fuel processing technology, Western Australia, v. 104, p. 356-364, 2012.

PRONOBIS, M. Evaluation of the influence of biomass co-combustion on boiler furnace slagging by means of fusibility correlations. Biomass and Bioenergy, Birmingham, v. 28, n. 4, p. 375383, 2005.

RIZVI, T. et al. Prediction of biomass ash fusion behaviour by the use of detailed characterisation methods coupled with thermodynamic analysis. Fuel, Rhode Island, v. 141, p. 275-284, 2015.

SAIDUR, R. et al. A review on biomass as a fuel for boilers. Renewable and sustainable energy reviews, Belfast, v. 15, n. 5, p. 2262-2289, 2011.

SOMMERSACHER, P.; BRUNNER, T.; OBERNBERGER, I. Fuel indexes: a novel method for the evaluation of relevant combustion properties of new biomass fuels. Energy \& Fuels, Washington, v. 26, n. 1, p. 380-390, 2011.

TEIXEIRA, P. et al. Uncertainty estimation to evaluate mass balances on a combustion system. Accreditation and Quality Assurance, Berlim, v. 17, n. 2, p. 159-166, 2012.

VAN LOO S.; KOPPEJAN, J. The handbook of biomass combustion and co-firing. London: Earthscan, 2008.

VASSILEV, S.V. et al. An overview of the organic and inorganic phase composition of biomass Fuel, Rhode Island, v. 94, p. 1-33, 2012.

VASSILEV, S. V. et al. An overview of the composition and application of biomass ash. Part 1. Phase-mineral and chemical composition and classification, Fuel, Rhode Island, v. 105, p. 4076, 2013.

WERTHER, J. et al. Combustion of agricultural residues. Progress in energy and combustion science, California, v. 26, n. 1, p. 1-27, 2000.

WIINIKKA, H.; GRÖNBERG, C.; BOMAN, C. Emissions of heavy metals during fixed-bed combustion of six biomass fuels. Energy \& Fuels, Washington, v. 27, n. 2, p. 1073-1080, 2013. 


\section{Contribuição de Autoria}

\section{1 - Martha Andreia Brand}

Engenheira Florestal, Dra.

https://orcid.org/0000-0001-5438-2081•martha.brand@udesc.br

Contribuição: Conceituação, Curadoria de dados, Análise Formal, Obtenção de financiamento, Investigação, Metodologia, Administração do projeto, Supervisão, Validação, Escrita - primeira redação, Escrita - revisão e edição

\section{2 - Reny Aldo Henne}

Engenheiro Mecânico, Me.

https://orcid.org/0000-0002-8970-1115・renyhenne@hotmail.com

Contribuição: Conceituação, Curadoria de dados, Análise Formal, , Investigação, Metodologia, Visualização de dados, Escrita - primeira redação, Escrita - revisão e edição

\section{3 - Viviane Aparecida Spinelli Schein}

Química, Dra.

https://orcid.org/0000-0002-5596-7898•viviane.schein@udesc.br

Contribuição: Conceituação, Curadoria de dados, Metodologia, Visualização de dados, Escrita - primeira redação, Escrita - revisão e edição

\section{4 - Ederson Rodrigues Pereira}

Químico, Dr.

https://orcid.org/0000-0002-2709-1294•edersonquimica@gmail.com

Contribuição: Curadoria de dados, Metodologia, Visualização de dados, Escrita primeira redação, Escrita - revisão e edição

\section{Como citar este artigo}

Brand, M. A.; Henne, R. A.; Schein, V. A. S.; Pereira, E. R. Mapeamento dos problemas associados à geração e tratamento das cinzas na combustão da biomassa florestal em caldeira. Ciência Florestal, Santa Maria, v. 31, n. 3, p. 1167-1192, 2021. DOI 10.5902/1980509835819. Disponível em: https://doi.org/10.5902/1980509835819. Acesso em: xx mês-abreviado. 2021. 